\section{Acetaminophen Potentiates Fear Processing: A Comparison Between Ancestral and Modern Threats}

\author{
Andrew C. Gallup 1,", Brianda K. L. Gagnon', Gillian \\ Perry', Omar Tonsi Eldakar ${ }^{2}$ \\ ${ }^{1}$ Department of Social and Behavioral Sciences, SUNY Polytechnic \\ Institute, Utica, NY, 13502 U.S.A. \\ ${ }^{2}$ Department of Biological Sciences, Nova Southeastern University, Ft. \\ Lauderdale, FL, 33314 U.S.A. \\ "Author for correspondence (a.c.gallup@gmail.com)
}

The painkilling medication acetaminophen produces a variety of unintended psychological effects. In particular, it has been shown to diminish varied forms of psychological distress by attenuating neural activity in the cerebral cortex and enhancing the signaling of serotonin. As a result, this overthe-counter medication appears to dampen overall affective processing and has been termed "an allpurpose emotion reliever." However, this drug may not necessarily modify all emotions in the same manner. Specifically, fear processing occurs rapidly within the amygdala and is governed by serotonin. Thus, by blunting cortical activity and facilitating serotonergic action, acetaminophen could in fact potentiate reactions to threatening stimuli. This study intersects with the fields of evolutionary psychology and psychopharmacology by investigating whether acetaminophen modulates responses to fearinducing stimuli that vary in ancestral relevance. We hypothesized that the more subcortical and prewired mechanisms controlling responses to recurring ancestral threats (snakes and spiders) would be more affected by this drug compared to learned threats of modern environments (handguns and hypodermic needles). In a double-blind placebo-controlled design $(N=94)$, acetaminophen significantly enhanced participants' evaluations and emotional reactions to threatening stimuli. In addition, ancestral threats were rated as both significantly more negative and emotionally arousing compared to modern threats. Contrary to our predictions, however, acetaminophen altered affective responses to ancestral and modern threats in a highly similar manner. We conclude that acetaminophen does not blunt overall affective processing, and call for further evolutionary-based research examining the various psychoactive effects of this commonly consumed over-the-counter painkiller.

\section{Keywords}

acetaminophen, emotional processing, evolutionary mismatch, evolutionary psychopharmacology, threat detection, neuromodulation

\section{Introduction}

Painkilling medications can profoundly improve human welfare by minimizing physical discomfort and suffering. However, the widespread use of over-the-counter (OTC) pain medications also presents a mismatch with adaptive mechanisms to decrease pain and distress (Gallup, 2019). Instead of diminishing pain through behavioral changes to address the sources of discomfort, people can now simply treat pain with OTC painkillers, which could lead to maladaptive health outcomes. Moreover, research shows that common OTC medications like acetaminophen (paracetamol, Tylenol) can produce a variety of additional unintended psychological effects that could result in further mismatch with our evolved psychology (Ratner et al., 2018)

Acetaminophen is the most widely used OTC pain reliever in the United States, and is present in almost 600 kinds of medicines (Kaufman et al., 2002). Research suggests that the painkilling properties of acetaminophen are largely attributed to the activation of the descending inhibitory serotoninergic pathways (e.g., Graham \& Scott 2005; Pickering et al., 2008). Although it remains unclear as to the precise mechanisms by which acetaminophen exerts an analgesic effect, involving serotonergic, opioid and cannabinoid systems (Graham et al., 2013), it is widely accepted that this drug reduces pain through central, rather than peripheral, nervous system mechanisms (Anderson 2008; Courade et al., 2001; Pickering et al., 2006; Smith 2009). As a result, acetaminophen has the potential to alter varied forms of perception, mood, cognition, and behavior.

DeWall et al. (2010) first revealed that daily use of acetaminophen reduced experiences of social distress by diminishing overall neural activity within cortical areas involved in both physical and social pain, i.e., the dorsal anterior cingulate cortex and anterior insula. Subsequent research has since expanded upon these findings, indicating that even a typical acute dose of acetaminophen can change how people experience emotional distress, process cognitive discrepancies, and evaluate stimuli in their environment (reviewed by Ratner et al., 2018). For example, studies have shown that a $1,000 \mathrm{mg}$ dose of this OTC drug can reduce negativity when thinking about one's own mortality (Randles et al., 2013), alleviate pain associated with decision-making (DeWall et al., 2015), and diminish the perceived challenge of tasks linked to social stress (Bershad et al., 2018).

Acetaminophen appears to inhibit general forms of evaluative processing through a blunting of cortical activity and the activation of serotoninergic pathways. For example, in one study, participants were administered 
either 1,000 mg of acetaminophen, or placebo, and asked to (1) rate the positive or negative valence of a series of images, and (2) respond to how much the images elicited an emotional reaction (Durso et al., 2015). Results showed that participants administered acetaminophen rated both positive and negative images less extremely and less emotionally arousing than those in a control condition, perhaps through the influencing of serotonin signaling in the brain. Acetaminophen has also been shown to reduce forms of both positive and negative empathy (Mischkowski et al., 2016, 2019), which is consistent with a central serotonergic mechanism (Way \& Keaveney, 2018). Taken together, this research indicates that acetaminophen might have a general blunting effect when it comes to evaluative and affective processing. In particular, Durso et al. (2015) suggest that acetaminophen might be considered "an allpurpose emotion reliever" (p. 756).

Here, we extend this research area by investigating whether acetaminophen modulates emotional states that are generated primarily by more domain-specific, subcortical regions governed by serotonin. Specifically, we tested whether acetaminophen alters fear processing through the evaluation sensitivity of threatening stimuli. Fear is a highly conserved psychological adaptation, and principally controlling by the amygdala, which is modulated by serotonin (Bocchio et al., 2016). The response to fear involves two basic pathways, a faster subcortical route to induce immediate action, and a longer, slower cortical route serving to mediate these responses after further evaluation (Méndez-Bértolo et al., 2016; Öhman et al., 2007). Thus, by blunting cortical activity (DeWall et al., 2015) and facilitating serotonergic action (Daya \& Anoopkumar-Dukie, 2000; Pini et al., 1996), acetaminophen could actually potentiate, rather than diminish, affective responses to certain types of threatening stimuli.

In particular, we tested for differences in evaluation sensitivity between two distinct classes of threatening stimuli: recurring ancestral threats (snakes and spiders) and modern threats (handguns and hypodermic needles). Humans appear biologically prepared to detect and respond to ancestral threats such as snakes and spiders, and only achieve fear of modern threats like guns and knives through learning and experience (Boyer \& Bergstrom, 2011; LoBue \& Rakison, 2013). Moreover, studies show that threatening animals produce stronger amygdala activation compared to weapons (Yang et al. 2012), and that images of snakes and spiders, but not guns, activate subcortical visual pathways in fear processing (Vida \& Behrmann, 2017). Thus, we hypothesized that the prewired neural substrates governing responses to recurring ancestral threats would be more greatly enhanced by the neuromodulation produced by this OTC drug. Since previous work indicates that females show greater fear of snakes and spiders (Bernstein \& Allen, 1969; Cornelius \& Averill, 1983; Fredrikson et al., 1996; Rakison, 2009), we also tested for sex differences in these effects.

\section{Methods}

Participants

A total of 101 college students participated in a study investigating the effects of acetaminophen on psychological processing from November 2018 to May 2019. Recruitment occurred through the psychology pool and campus flyers on a public research university in the northeastern United States. Data from one participant was removed upon discovering they were 17 years old, and another participant did not complete the study. Of the remaining sample, 63 identified as male and 31 identified as female $(N=$ 94 ; mean age $19.55 \pm 2.56$ ). Participants received either course research credit or \$20 in compensation. Exclusion criteria included any risk factors associated with taking acetaminophen (e.g., currently taking a drug containing acetaminophen, history of liver disorder, an allergic reaction to acetaminophen or history of alcohol abuse) or a history of medical or psychiatric illness. The experiment was conducted in accordance with approved human ethics guidelines, and participants provided informed consent prior to the study. The local Institutional Review Board approved this research (\#2018-08-07-1).

\section{Procedure}

Coin flip determined whether participants consumed a $10 \mathrm{ml}$ liquid containing $1,000 \mathrm{mg}$ of acetaminophen $(N$ $=46)$ or a matched placebo solution $(N=48)$. Similar to Mischkowski et al. (2016), acetaminophen and placebo solutions were prepared by Pharmacy Specialists Compounding Pharmacy (Altamonte Springs, Florida). The drug solution consisted of acetaminophen $(100 \mathrm{mg} / \mathrm{ml})$ dissolved in Ora-Plus suspension liquid and flavored with Ora-Sweet Syrup and the placebo solution consisted of Avicel Microcrystalline powder $(100 \mathrm{mg} / \mathrm{ml})$ dissolved in the same vehicle. Participants and researchers were blind to the experimental condition. Participants were asked to refrain from eating for at least three hours prior to the study, and following administration participants waited for a period of 60 minutes for drug absorption (Durso et al., 2015).

Thereafter, participants initially completed a short visual disengagement task, which was part of a separate study (Gallup et al., 2020), before an image rating task similar in procedure to Durso et al. (2015) was presented on a computer monitor using SuperLab 5 (Cedrus Corporation). Stimuli for the rating task included fearrelevant, threatening images randomly intermixed with an equal number of matched control images. In particular, two types of threatening stimuli were included: recurring ancestral threats and modern threats. The ancestral threatening images were of snakes and spiders, while the modern threats were images of handguns and hypodermic needles. The control stimuli included frogs, butterflies, hairdryers, and pens. All images were acquired online using image searches on Google. Seven images were presented from each category (56 total), and all were set to grayscale.

During testing, participants rated one image at a time, and the order of presentation was randomized for each participant. Following the methods of Durso et al. (2015), participants were instructed to rate how positive or negative they thought each image was on an 11-point scale $(5=$ extremely positive; $-5=$ extremely negative). The images were standardized to approximately the same size $(7.62 \times 11.43 \mathrm{~cm})$ and presented in the center of the screen, with the rating scale depicted directly under the image for reference (Fig. 1). Participants then also rated 


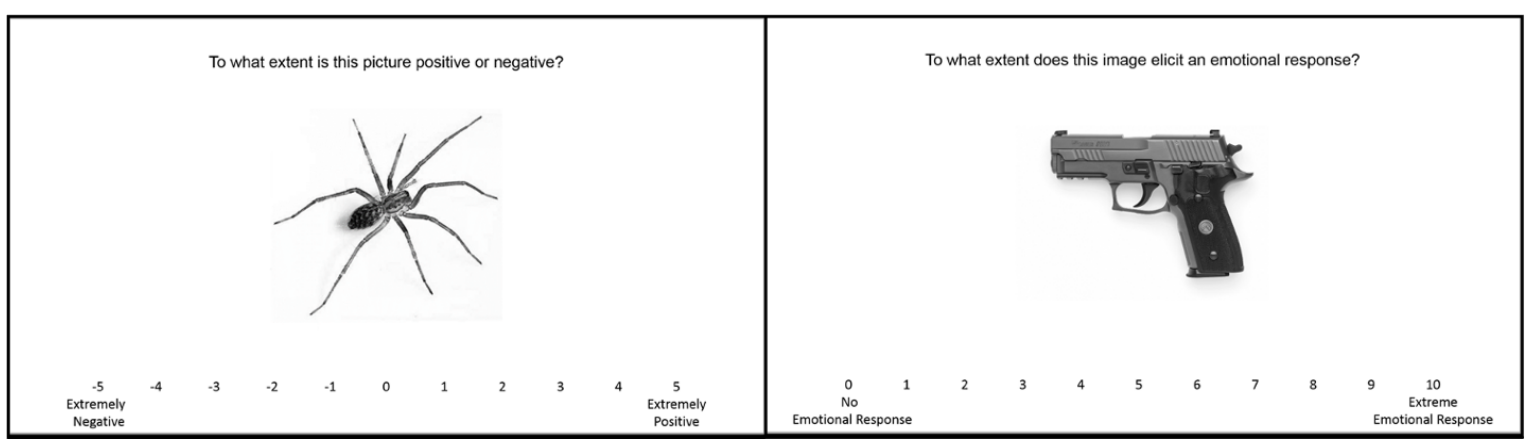

Figure 1. Examples of the ancestral and modern threatening stimuli, and how valence and arousal were evaluated.

how much the same image elicited an emotional response on an 11-point scale $(0=$ no emotional response; $10=$ extreme emotional response). Similarly, this rating scale was presented directly under the image for reference (Fig. 1). All ratings were provided using the number pad on a keyboard, and participants proceeded to new images/ questions by clicking on the screen with the computer mouse.

\section{Analyses}

Participant ratings were averaged for each of the threat categories due to high consistency across responses to the snake and spider images (positive/negative evaluation $\alpha$ $=.946$; emotional arousal $\alpha=.964$ ) and the handgun and hypodermic needle images (positive/negative evaluation: $\alpha=.892$; emotional arousal: $\alpha=.911$ ). Statistical tests included separate 2 (threat: ancestral/modern) x 2 (sex: male/female) x 2 (treatment: acetaminophen/placebo) mixed ANOVAs both for the positive/negative valence and emotional arousal response ratings. Analyses were conducted in SPSS v.27, and consisted of 2-tailed tests with the alpha set to .05 .

\section{Results}

\section{Positive/Negative Valence}

There was a significant main effect of threat condition $\left(F_{1,90}\right.$ $\left.=4.318, p=.041, \eta_{\mathrm{p}}{ }^{2}=.046\right)$, with ancestral threats being rated as more negative than modern threats. There was also a main effect of drug treatment $\left(F_{1,90}=4.053, p=.047, \eta_{\mathrm{p}}{ }^{2}\right.$ $=.043)$, with participants in the acetaminophen condition rating the threatening stimuli as more negative (Fig. 2a).
There was no significant difference between males and females $\left(F_{1,90}=3.325, p=.072, \eta_{\mathrm{p}}{ }^{2}=.036\right)$, nor were there any interactions between these factors $(p s>.05)$.

\section{Emotional Arousal}

There was a significant main effect of threat condition $\left(F_{190}\right.$ $=13.495, p<.001, \eta_{\mathrm{p}}^{2}=.130$ ), with ancestral threats being rated as more emotionally arousing (i.e., fear-inducing) than modern threats. There was also a significant main effect of drug treatment $\left(F_{1,90}=4.557, p=.035, \eta_{\mathrm{p}}{ }^{2}=\right.$ .048), with participants in the acetaminophen condition indicating a greater emotional reaction to these images (Fig. 2b). Moreover, there was a significant main effect of $\operatorname{sex}\left(F_{1,90}=8.955, p=.004, \eta_{\mathrm{p}}{ }^{2}=.090\right)$, with females rating threats as more emotionally arousing ( $M=4.53$ vs. 3.12$)$. However, there were no significant interactions between these factors $(p s>.05)$.

\section{Discussion}

Numerous studies have now examined the psychoactive effects of acetaminophen (Ratner et al., 2018), with most attention paid towards aspects of social pain (DeWall et al., 2010; Slavich et al., 2019) and basic affective processes (Durso et al., 2015; Gallup et al., 2020; Mischkowski et al., 2019). Here, we demonstrate that the psychological effects of this drug extend to the evaluation of threatening stimuli, albeit counter to the general patterns previously documented in the literature with regards to psychological distress. Participants administered acetaminophen in this study reported significantly more negative evaluations and increased emotional arousal in response to threatening
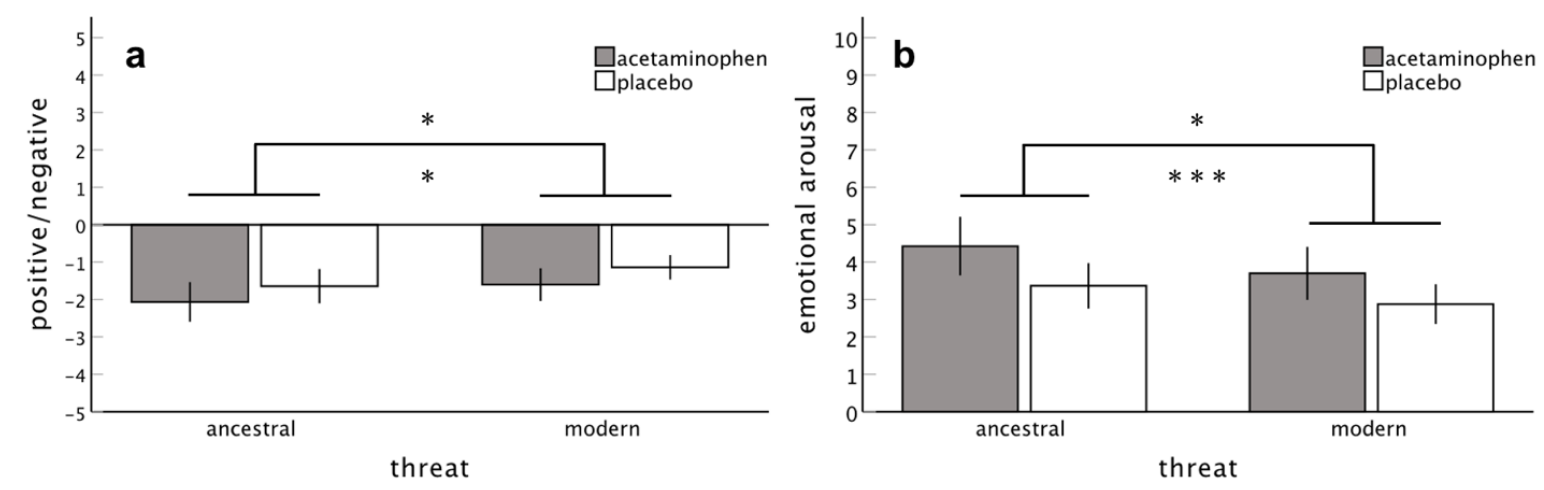

Figure 2. Threatening stimuli were rated as more negative (a) and induced a greater emotional response (b) in the acetaminophen condition. Means $\pm 95 \%$ CI presented; $* p<.05 ; * * * p<.001$. 
images. The ancestral threats (snakes and spiders) were rated significantly more negative and arousing than the modern threats (handguns and hypodermic needles), but, contrary to our predictions, acetaminophen altered the responses to ancestral and modern threats in a similar manner.

These enhancing - as opposed to dulling-effects of acetaminophen provide a stark contrast to previous studies and in particular the findings of Durso et al. (2015), which showed an overall blunting of affective processing in response to both positive and negative stimuli. In this previous study, the blunting effects from acetaminophen were most evident for images that were either extremely negative or extremely positive, with little to no change for moderately pleasant and unpleasant images. While the threatening stimuli used in the current study were clearly negative based on participant ratings (Fig. 2a), the combined responses suggest they were perceived as moderately, rather than extremely, unpleasant (Lang et al., 1997). Nonetheless, this distinction does not account for why the responses to the stimuli in the current study were potentiated rather than being unchanged or just weakly altered as shown previously (Durso et al., 2015). Instead, we suggest that differences in the nature of the stimuli are likely responsible for the contrasting results. The images selected for the current study were all focal images of salient threatening stimuli associated with fear (Bernstein \& Allen, 1969; Fredrikson et al., 1996), while the unpleasant images used by Durso et al. (2015), which came from the International Affective Picture System (Lang et al., 1997), included a variety of contexts and stimuli that likely induced a range of negative emotions.

Independent of drug treatment, participants in the current study rated the ancestral stimuli more negative and experienced greater emotional arousal compared to when evaluating contemporary threats. These results were expected as snakes and spiders represent recurring evolutionary threats, favoring corresponding neurological adaptations for rapid detection and response (Dinh et al., 2018; Van Le et al., 2013). Contrary to our predictions, however, the effects from acetaminophen did not vary as a function of the ancestral relevance of the stimuli. This suggests that acetaminophen modulates more general processes involved in the perception and evaluation of threatening stimuli. Consistent with past research, females rated the threatening stimuli as more emotionally arousing, though the effect of threat category and drug treatment did not vary between the sexes.

Further research is needed to uncover, mechanistically, how acetaminophen potentiates negative evaluations and arousal to threatening images. Previous research has shown that as conditions allow conscious processing of fear-relevant stimuli, as was the case here, cortical activity is enhanced and appears to inhibit the amygdala response (Öhman, 2005). Given that acetaminophen attenuates cortical activity (DeWall et al., 2010), this could impair the mitigation of fear initiated by the fast pathway in the amygdala (Méndez-Bértolo et al., 2016), giving rise to the pattern of results observed here. Similar to past researchers studying the psychoactive effects of acetaminophen (Durso et al., 2015; Mischkowski et al., 2016; Pearson et al., 2018), we suspect serotonin also plays a key role. Acetaminophen facilitates serotonergic signaling (Pini et al., 1996) and raises serotonin in the brain (Daya \& AnoopkumarDukie, 2000), and the amygdala is modulated by this neurotransmitter (Bocchio et al., 2016). In particular, serotonin circuits have been shown to govern fear and anxiety in the amygdala (Marcinkiewcz et al., 2016), and pharmaceutical drugs that increase the effects of serotonin can increase fear after acute treatment (Burghardt et al., 2004).

In summary, we provide evidence for a novel psychoactive effect produced by acetaminophen: the potentiation of affective reactions to fear-related stimuli. Although this represented a small effect, and the study was limited to assessments of a relatively small number of heterogeneous visual stimuli and did not capture explicit measures of fear, our results clearly do not support previous research indicating that acetaminophen blunts overall affective processing. The psychological literature on acetaminophen (Ratner et al., 2018) suggests a complex picture when predicting and understanding the effects of this commonly used medication, and thus we call for additional research examining how this OTC drug could result in further mismatch with our evolved psychology.

\section{Acknowledgements}

This research was generously supported by the SUNY Polytechnic Institute Research Seed Grant Program (\#81825).

\section{References}

Anderson, B. J. (2008). Paracetamol (Acetaminophen): mechanisms of action. Pediatric Anesthesia, 18(10), 915-921. https://doi.org/10.1111/j.14609592.2008.02764.x

Bernstein, D. A., \& Allen, G. J. (1969). Fear survey schedule (II): Normative data and factor analyses based upon a large college sample. Behaviour Research and Therapy, 7(4), 403-407. https://doi. org/10.1016/0005-7967(69)90072-2

Bershad, A. K., Miller, M. A., Norman, G. J., \& de Wit, H. (2018). Effects of opioid-and non-opioid analgesics on responses to psychosocial stress in humans. Hormones and Behavior, 102, 41-47. https://doi.org/10.1016/ j.yhbeh.2018.04.009

Bocchio, M., McHugh, S. B., Bannerman, D. M., Sharp, T., \& Capogna, M. (2016). Serotonin, amygdala and fear: Assembling the puzzle. Frontiers in Neural Circuits, 10, 24. https://doi.org/10.3389/fncir.2016.00024

Boyer, P., \& Bergstrom, B. (2011). Threat-detection in child development: An evolutionary perspective. Neuroscience \& Biobehavioral Reviews, 35(4), 10341041. https://doi.org/10.1016/j.neubiorev.2010.08.010

Burghardt, N. S., Sullivan, G. M., McEwen, B. S., Gorman, J. M., \& LeDoux, J. E. (2004). The selective serotonin reuptake inhibitor citalopram increases fear after acute treatment but reduces fear with chronic treatment: A comparison with tianeptine. Biological Psychiatry, 55(12), 1171-1178. https://doi.org/10.1016/ j.biopsych.2004.02.029

Cornelius, R. R., \& Averill, J. R. (1983). Sex differences in fear of spiders. Journal of Personality and Social Psychology, 45(2), 377-383. https://doi. org/10.1037/0022-3514.45.2.377

Courade, J. P., Besse, D., Delchambre, C., Hanoun, N., 
Hamon, M., Eschalier, A., Caussade, A., \& Cloarec, A. (2001). Acetaminophen distribution in the rat central nervous system. Life Sciences, 69(12), 1455-1464. https://doi.org/10.1016/S0024-3205(01)01228-0

Daya, S., \& Anoopkumar-Dukie, S. (2000). Acetaminophen inhibits liver tryptophan-2,3-dioxygenase activity with a concomitant rise in brain serotonin levels and a reduction in urinary 5-hydroxyindole acetic acid. Life Sciences, 67(3), 235-240. https://doi.org/10.1016/ S0024-3205(00)00629-9

DeWall, C. N., Chester, D. S., \& White, D. S. (2015). Can acetaminophen reduce the pain of decision-making? Journal of Experimental Social Psychology, 56, 117120. https://doi.org/10.1016/j.jesp.2014.09.006

DeWall, C. N., MacDonald, G., Webster, G. D., Masten, C. L., Baumeister, R. F., Powell, C., Combs, D., Schurtz, D. R., Stillman, T. F., Tice, D. M., \& Eisenberger, N. I. (2010). Acetaminophen reduces social pain: Behavioral and neural evidence. Psychological Science, 21(7), 931-937. https://doi.org/10.1177/0956797610374741

Dinh, H. T., Nishimaru, H., Matsumoto, J., Takamura, Y., Le, Q. V., Hori, E., Maior, R. S., Tomaz, C., Tran, A. H., Ono, T. \& Nishijo, H. (2018). Superior neuronal detection of snakes and conspecific faces in the macaque medial prefrontal cortex. Cerebral Cortex, 28(6), 2131-2145. https://doi.org/10.1093/ cercor/bhx 118

Durso, G. R. O., Luttrell, A., \& Way, B. M. (2015). Over-the-counter relief from pains and pleasures alike: Acetaminophen blunts evaluation sensitivity to both negative and positive stimuli. Psychological Science, 26(6), 750-758. https://doi. org $/ 10.1177 / 0956797615570366$

Fredrikson, M., Annas, P., Fischer, H., \& Wik, G. (1996). Gender and age differences in the prevalence of specific fears and phobias. Behaviour Research and Therapy, 34(1), 33-39. https://doi.org/10.1016/00057967(95)00048-3

Gallup, A. C. (2019). Over-the-counter painkillers and evolutionary mismatch. Frontiers in Psychology, 10, 686. https://doi.org/10.3389/fpsyg.2019.00686

Gallup, A. C., Gagnon, B. K. L., Rosic, B., \& Eldakar, O. T. (2020). Acetaminophen does not alter the early processing of emotional facial expressions: An eyetracking study. EvoS Journal, 11, 34-43. https:// evostudies.org/wp-content/uploads/2020/05/Gallup_ et_al_Vol11SpIss1.pdf

Graham, G. G., Davies, M. J., Day, R. O., Mohamudally, A., \& Scott, K. F. (2013). The modern pharmacology of paracetamol: Therapeutic actions, mechanism of action, metabolism, toxicity and recent pharmacological findings. Inflammopharmacology, 21(3), 201-232. https://doi.org/10.1007/s10787-0130172-x

Graham, G. G., \& Scott, K. F. (2005). Mechanism of action of paracetamol. American Journal of Therapeutics, 12(1), 46-55. https://doi.org/10.1097/00045391200501000-00008

Kaufman, D. W., Kelly, J. P., Rosenberg, L., Anderson, T. E., \& Mitchell, A. A. (2002). Recent patterns of medication use in the ambulatory adult population of the United States: The Slone survey. JAMA, 287(3), 337-344. https://doi.org/10.1001/jama.287.3.337

Lang, P. J., Bradley, M. M., \& Cuthbert, B. N. (1997). International affective picture system (IAPS): Technical manual and affective ratings. NIMH Center for the Study of Emotion and Attention, 1, 39-58. https://www2.unifesp.br/dpsicobio/adap/instructions. pdf

LoBue, V., \& Rakison, D. H. (2013). What we fear most: A developmental advantage for threat-relevant stimuli. Developmental Review, 33(4), 285-303. https://doi. org/10.1016/j.dr.2013.07.005

Marcinkiewcz, C. A., Mazzone, C. M., D’Agostino, G., Halladay, L. R., Hardaway, J. A., DiBerto, J. F., Navarro, M., Burnham, N., Crisiano, C., Dorrier, C. E., Tipton, G. J., Ramakrishnan, C., Kozicz, T., Deisseroth, K., Thiele, T. E., McElligott, Z. A., Holmes, A., Heisler, L. K., \& Kash, T. L. (2016). Serotonin engages an anxiety and fear-promoting circuit in the extended amygdala. Nature, 537(7618), 97-101. https://doi.org/10.1038/nature19318

Méndez-Bértolo, C., Moratti, S., Toledano, R., Lopez-Sosa, F., Martínez-Alvarez, R., Mah, Y. H., Vuilleumier, P., Gil-Nagel, A., \& Strange, B. A. (2016). A fast pathway for fear in human amygdala. Nature Neuroscience, 19(8), 1041-1049. https://doi.org/10.1038/nn.4324

Mischkowski, D., Crocker, J., \& Way, B. M. (2016). From painkiller to empathy killer: Acetaminophen (paracetamol) reduces empathy for pain. Social Cognitive and Affective Neuroscience, 11(9), 13451353. https://doi.org/10.1093/scan/nsw057

Mischkowski, D., Crocker, J., \& Way, B. M. (2019). A social analgesic? Acetaminophen (paracetamol) reduces positive empathy. Frontiers in Psychology, 10, 538. https://doi.org/10.3389/fpsyg.2019.00538

Öhman, A. (2005). The role of the amygdala in human fear: Automatic detection of threat. Psychoneuroendocrinology, 30(10), 953-958. https:// doi.org/10.1016/j.psyneuen.2005.03.019

Öhman, A., Carlsson, K., Lundqvist, D., \& Ingvar, M. (2007). On the unconscious subcortical origin of human fear. Physiology \& Behavoir, 92(1-2), 180-185. https://doi.org/10.1016/j.physbeh.2007.05.057

Pearson, R., Koslov, S., Hamilton, B., Shumake, J., Carver, C. S., \& Beevers, C. G. (2018). Acetaminophen enhances the reflective learning process. Social Cognitive and Affective Neuroscience, 13(10), 10291035. https://doi.org/10.1093/scan/nsy074

Pickering, G., Estève, V., Loriot, M. A., Eschalier, A., \& Dubray, C. (2008). Acetaminophen reinforces descending inhibitory pain pathways. Clinical Pharmacology \& Therapeutics, 84(1), 47-51. https:// doi.org/10.1038/sj.clpt.6100403

Pickering, G., Loriot, M. A., Libert, F., Eschalier, A., Beaune, P., \& Dubray, C. (2006). Analgesic effect of acetaminophen in humans: First evidence of a central serotonergic mechanism. Clinical Pharmacology \& Therapeutics, 79(4), 371-378. https://doi.org/10.1016/ j.clpt.2005.12.307

Pini, L. A., Sandrini, M., \& Vitale, G. (1996). The antinociceptive action of paracetamol is associated with changes in the serotonergic system in the rat brain. European Journal of Pharmacology, 308(1), 31-40. https://doi.org/10.1016/0014-2999(96)00261-0

Rakison, D. H. (2009). Does women's greater fear of snakes and spiders originate in infancy? Evolution and Human Behavior, 30(6), 438-444. https://doi. org/10.1016/j.evolhumbehav.2009.06.002

Randles, D., Heine, S. J., \& Santos, N. (2013). The common pain of surrealism and death: Acetaminophen reduces compensatory affirmation following meaning threats. Psychological Science, 24(6), 966-973. https://doi. org/10.1177/0956797612464786 
Ratner, K. G., Kaczmarek, A. R., \& Hong, Y. (2018). Can over-the-counter pain medications influence our thoughts and emotions? Policy Insights from the Behavioral and Brain Sciences, 5(1), 82-89. https:// doi.org/10.1177/2372732217748965

Slavich, G. M., Shields, G. S., Deal, B. D., Gregory, A., \& Toussaint, L. L. (2019). Alleviating social pain: A double-blind, randomized, placebo-controlled trial of forgiveness and acetaminophen. Annals of Behavioral Medicine, 53(12), 1045-1054. https://doi.org/10.1093/ $\mathrm{abm} / \mathrm{kaz} 015$

Smith, H. S. (2009). Potential analgesic mechanisms of acetaminophen. Pain Physician, 12(1), 269-280. https://www.painphysicianjournal.com/current/pdf?ar ticle $=$ MTE4NA $\% 3 \mathrm{D} \% 3 \mathrm{D} \&$ journal $=47$

Van Le, Q., Isbell, L. A., Matsumoto, J., Nguyen, M., Hori, E., Maior, R. S., Tomaz, C., Tran, A. H., Ono, T., \& Nishijo, H. (2013). Pulvinar neurons reveal neurobiological evidence of past selection for rapid detection of snakes. Proceedings of the National Academy of Sciences of the United States of America, 110(47), 19000-19005. https://doi. org/10.1073/pnas.1312648110

Vida, M. D., \& Behrmann, M. (2017). Subcortical facilitation of behavioral responses to threat. Scientific Reports, 7: 13087. https://doi.org/10.1038/s41598-01713203-8

Way, B. M., \& Keaveney, A. (2018). Biochemical contributions to interpersonal emotion dynamics. In A. K. Randall, \& D. Schoebi (Eds.), Interpersonal emotion dynamics in close relationships (Studies in emotion and social interaction, pp. 93-109). Cambridge University Press. https://doi. org/10.1017/9781316822944.007

Yang, J., Bellgowan, P. S. F. \& Martin, A. (2012). Threat, domain-specificity, and the human amygdala. Neuropsychologia, 50(11), 2566-2572. https://doi. org/10.1016/j.neuropsychologia.2012.07.001

\section{Appendix}

The datasets generated during and/or analyzed during the current study are available in the Nova Southeastern University repository: https://nsuworks.nova.edu/cnso_ bio_datasets/2/ 